Journal of Computer Science 8 (8): 1389-1396, 2012

ISSN 1549-3636

(C) 2012 Science Publications

\title{
A Comparative Study of Enterprise Resource Planning Vs Service Oriented Architecture in Small Medium Enterprises
}

\author{
Ali Taei Zadeh, Muriati Mukhtar and Shahnorbanun Sahran \\ Department of Industrial Computing, FTSM Faculty, UKM, Kuala Lumpur, Malaysia
}

\begin{abstract}
Problem statement: Enterprise Resource Planning (ERP) systems have such an important role in global success and become more complex over time. Small Medium Enterprises (SMEs) follow large enterprises in using ERP systems while ERPs have not addressed the SME's specific challenges such legacy systems as the main assets in SMEs that have not considered in ERP solutions as well as special situation requirements, budget and employee's knowledge. Approach: This study demonstrates and discusses most important criteria of ERP-SME compatibility that extracted based on literature review and survey results. So that a clear view of ERP success in SMEs is presented. Service Oriented Architecture (SOA) is evaluated according to survey that has been done within number of SMEs to reveal its power in addressing SMEs' challenges based on extracted criteria and systematically comparison. Results: The results of this study provide SMEs with valuable analysis that will guide them to make correct and effective changes in their current information systems. According to analyzing the SMEs criteria and ERP characteristics a set of points as guidelines of information systems implementation in SMEs were presented. Moreover, a systematically comparison of suitability of SOA on extracted criteria has been done. Conclusion: Evaluating results of the ERP systems that are based on object oriented versus SOA based systems will be useful to gradation the SMEs performance.
\end{abstract}

Key words: Enterprise Resource Planning (ERP), Service Oriented Architecture (SOA), Enterprise Resource Planning (ERP), Small Medium Enterprises (SMEs)

\section{INTRODUCTION}

Small Medium Enterprises (SMEs) are biggest portion of each economy (Levy and Powell, 1998). The number and importance of SMEs increased in last decades (Levy and Powell, 1998). Number of employees is one of the major factors of SMEs as a small enterprise has no more than 100 employees and on the other hand a medium size enterprise encompasses no more than 500 employees. SMEs by their nature lack in resources such as high skills, budget, training and so on. Therefore, any solution should be consistent with their constraints, for example due to lack of employee knowledge in SMEs, designing the business processes is a challenging task because the majority of the standards are compatible with large enterprises, thus it is essential to select a smaller scale method to Business Process Modeling (BPM) in SMEs (Nielen et al., 2010).

Nowadays, SMEs tends to use information systems as a tool to improving their business development as well as participating in competing with other companies. The main issue in SMEs is to gain the business goals in such rigid environment. Consequently, intensifying of applying IT tools in SMEs depends on their effectiveness and benefits that should be tangible in short time by enterprise and specifically the managers themselves (Nach and Lejeune, 2008).

Besides, Enterprise Recourse Planning (ERP) systems have widely used in large enterprises as a common software to support the most business functionalities (Huang and Palvia, 2001). However, in comparison with large enterprises, ERP is new concept among SMEs and faced considerable challenges that their origin are in SME's nature such as budget and expert staff (Huang and Palvia, 2001; Yuanqiang et al., 2009). Inconsistency of ERP systems that have made and customized for large enterprises with SME's structure leads to hindered them to obtain full benefits of information technology. This attribute of ERP is rooted in ERP vendor's strategies as most of ERP customers are large companies with requirements that comes from particular situation of theirs (Yen et al., 2002). Consequently, until now SMEs could not achieve ERP benefits in total (Botta-Genoulaz and Millet, 2005). Realizing the benefits is strongly related to enterprise's nature and their strategies. The majority

Corresponding Author: Ali Taei Zadeh, Department of Industrial Computing, FTSM Faculty, UKM, Kuala Lumpur, Malaysia 


\section{J. Computer Sci., 8 (8): 1389-1396, 2012}

of large enterprises consider the ERP as investment for more than 5 years while SME's manager tends to see the results of any investment in short time (BottaGenoulaz and Millet, 2005). In addition, through literature review and real-world case studies some other crucial factors are revealed such as ERP's complexity, vendor dependency, interoperability and so on that each of which have influenced on the outcomes of ERP implementations.

One of the main motivations of widely ERP adoption is that it promises to embed agility and flexibility in the organization. Generally the main goal of ERP's customers has been defined as the integration of applications and enterprise business processes (Brehm et al., 2009). Service Oriented Architecture (SOA) as a new paradigm brings agility and flexibility and becomes pioneer in the today's enterprise information system structures. It is deigned to build services based on business goals and this attribute could be considered as distinct feature of SOA. This factor leverage the ITbusiness alignment which lack of it hinders the enterprise success (Kohlborn et al., 2009).

In addition, SOA unlike ERP systems could use existing systems without forcing the enterprise to build their services from scratch by leveraging existing software, data and this ability reduces the amount of budget that required for SOA transformation project, decrease risks of designing new systems. Moreover, SOA has ability to give independency from vendors to users that also is a determinative factor considered in information selection for an SME (Kelliher and Henderson, 2006).

The main goal of this study is to evaluate the amount of consistency of SMEs with ERP systems and service oriented solutions. In order to achieve this goal the ERP-SME consistency are debated. This idea promises to address the lacks of the SME familiarity and is an encourage point into new techniques such as SOA that is widely used architecture with introducing potentials and requirements.

In general, the contribution promotes SMEs to rearrange their enterprise systems based on service solutions instead of object oriented based ERP systems.

This study is organized into 5 sections. Section 2 is focused into ERP characteristics and SMEs situations in implementation ERP that presented set of criteria is discussed in of this study as section 3. Next, the results that achieved from previous methods' comparisons is places in section 4 followed by conclusion and references.

\section{MATERIALS AND METHODS}

In this study the effective challenges of applying ERP in SMEs will be discussed and then evaluation of
SME's challenges in using ERP systems as reasons of holdup in IT development has been done. Moreover, necessities of eligible information systems those which have appeared as lacks in the SME and has not addressed until now. Next, major characteristics that should be addressed and covered within any information system in SMEs are discussed. Next, based on those characteristics main challenges points of ERP implementation in SME environment are presented. These points are effective in detection and determination of what features exactly could be matched with SME's situation. According to the extracted characteristics in previous steps a systematically comparison between ERP and SMEs criteria and also SOA and SME criteria has been done. The results could be as guideline to adopt the suitable tool in SMEs environments. Thus this research is based on qualitative study of SMEs by analyzing previous results of implementing ERP systems and also feedbacks of SOA adoptions in large enterprises. In addition, the results of survey have been used that is conducted within 20 SMEs to identify the situational variables and their criteria in information systems adoption.

ERP characteristics: Majority of enterprises use variety of application to cover their lacks in business, gain more business agility and overcome in their competition in business. As result the complexity of IT environment turns into the main problem of enterprises (Hopkins and Jenkins, 2008). Over last years the IT development trends shows decrease in the IT systems relationships and thereby their complexity of integrating them into comprehensive software such as ERP. Zaitun and Zaini (2008) defined ERP as standard software that is comprehensiveness and highly integrated. Integration means integrating islands applications that cover enterprise business processes in variety of enterprise areas. Enterprise Application Integration (EAI) is a high level enterprise subject that needs revising enterprise strategy (Themistocleous and Irani, 2000). This ability offers more efficiency to the business process and especially to interconnected processes between enterprises sections. ERP software supports this idea and solve application islands problem (Oliveira et al., 2011). It should be considered that completely integration of enterprise application within an ERP system requires preparation of all ERP modules.

Also ERP systems provide comprehensive and consistent parts software in variety of fields as one product. This factor leads to decrease data redundancy and amount of data entry. As by using one common core of ERP system other parts of ERP could use required data without data entry such as staff personnel 


\section{J. Computer Sci., 8 (8): 1389-1396, 2012}

information, products attributes and so on. Analyzing ERP disadvantages in SME's environment will be discussed in discussion section.

\section{RESULTS AND DISCUSSION}

SME criteria: SMEs try to get its chunk from ERP by following large enterprises or manage by magazine method to select ERP software, without a systematic study in proportion of this type of software with SME's situation. However, they could not achieve ERP's benefits because of their specific capabilities and incapabilities (Haddara and Zach, 2011).

Main prerequisite for successful implementation of ERP are availability for experts, budget, long term strategic plan. Lack of those parameters in SMEs causes in losing to utilization suitable information system and thus losing their competitive power while using unsuitable information system (Quiescenti et al., 2006). We will illustrate the important factors for SMEs in adoption an effective information system that extracted from literature review and are vendor dependency, complexity, interoperability, short time to implement and legacy systems.

Vendor dependency means the amount of user dependency to the software vendor in any stage from support, data preparation, hardware platform and any customization. This could be a key of systems failure in SME's IT life, because mostly vendors consider large enterprises requirements and also their budget. The main challenge could be less attention to small enterprises in software customization (Cruz-Cunha, 2010).

Complexity could be defined as level of understandability, learn ability and usability (Tan et al., 2009). It is one of effective factors so that it could decrease the performance and efficiency of IT in an enterprise. This factor has direct relationship with amount of activities that encapsulated within software. In last two decades number of applications and relationships between their parts increased the complexity as in the first glance, integration and abstraction to decrease or hide the complexity became a necessity.

Interoperability means the ability to use the software capabilities without dependency on special hardware or software such as operating system. Precisely, a solution should not only independent in special software or hardware but in specific network's or based on specific protocols too. Interoperability could be determined in different levels for example ability to connecting with standard protocols or ability to data transforming by standard formats.
Short time to implement every project or plan in SMEs should appear a clear output in short time. This is a constant rule in any investment in SMEs as they cannot tolerate a long time to see the benefits of an investment. Besides, the frequency of environmental factors changing force expectation of getting the result of a plan in a short time.

Return of Investment (ROI) indicates the level of cost saving achieved after ERP implementation (Zdravkovi et al., 2007). SMEs resources do not permit waiting for a long term period so in most of SMEs there is no long term strategies (Sahran et al., 2010). Also unlike big enterprises they do not seek to achieve a little efficiency upgrading (e.g., 5\% of improvement) by implementing a specific solution. So, small applications that provide rapid results and benefits to the enterprise are preferred in SMEs. In many cases those application are emergency and comes to survive portion of enterprise with rapid feedbacks.

Legacy systems are main assets in SME's IT life cycle. Lack of budget, employee's habits of working with specific software and also SME's culture justify paying considerable attention to preserving legacy systems. The goal in any software transformation in SMEs should be remaining most as possible of legacy systems by reusing the code, design and data to decrease the time and budget needed for implementing new system.

Above factors could organize in high level categorization that is more close to strategic planning. We propose business, technical and economic aspects as three main factor in top management of an SME (Damaskopoulos and Evgeniou, 2003). Figure 1 shows relations of those aspects with mentioned factors. As it is obvious, Fig. 1 demonstrates that economic aspect takeover the most relations with information systems' success factors. Factors that have numbered 3, 4, 5 and 6 have positive effect that means straight relationship with economic aspect. However, among them 3 and 4 have more technical characteristics than 5 and 6 that tend more to business subjects. Generally, this result is not a surprise, so that most concern in SMEs comes from lacks in budget. This aspect should consider strongly in any SME's solution. Also factors that have numbered 2, 3 and 6 affect the technical aspect of the enterprise. Complexity is one of the main barriers in information system acceptance and implementation in SMEs (Tan et al., 2009). Complexity factor could be determinant in technical developing or understanding the application as well as in business aspect that could acts as hinder of changing in modules of information systems that correspond to a specific business rules and decrease the flexibility. 


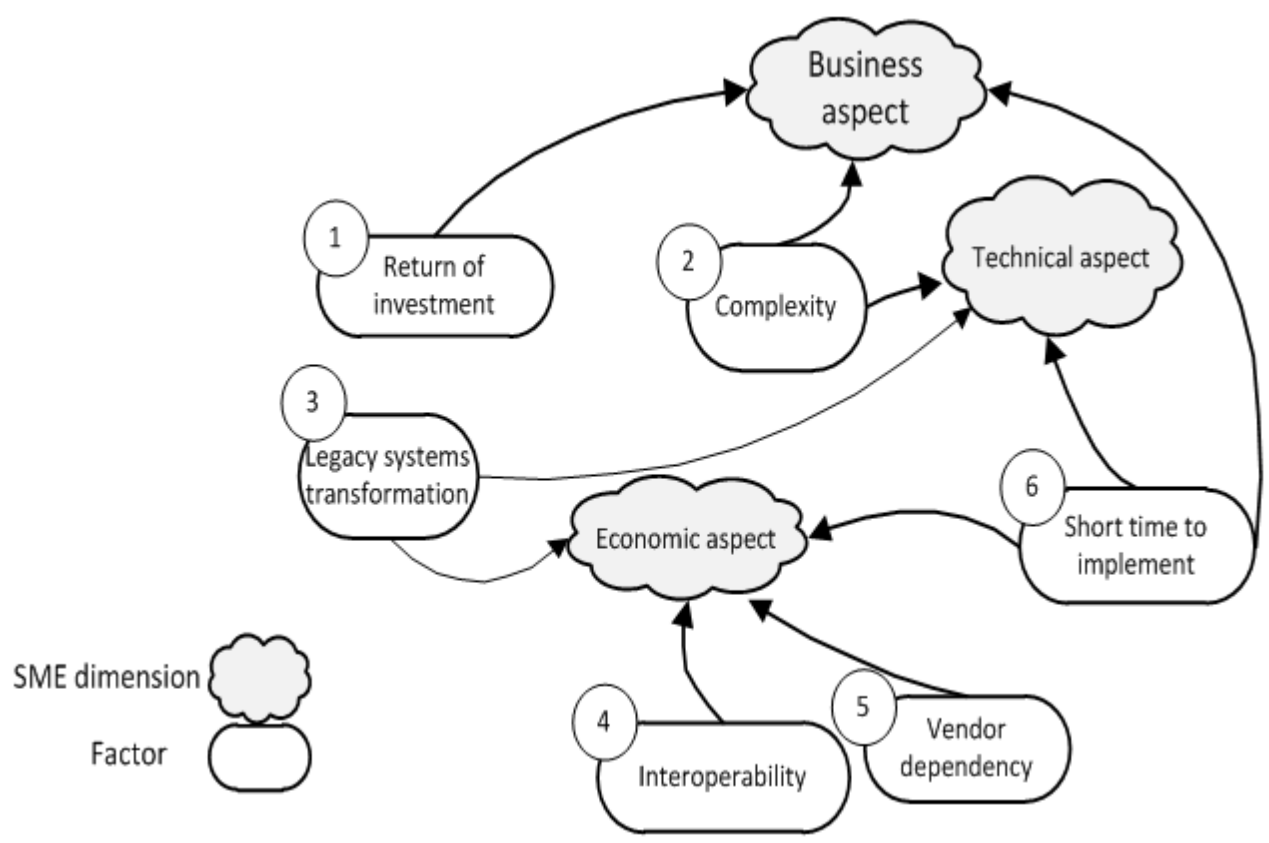

Fig. 1: Relations of SME's high level aspects and information system's success factors

Legacy systems has considered that tied to technical aspect, since legacy systems transformation is about steps and roadmap that prepare the transformation from existing systems to the new technology without losing in previous experiences, data and management facilities.

Before ERP, incompatibility in enterprise applications, particularly input, output and data format of them resist integration and upgrading of information systems (Morabito et al., 2005). Now inconsistency between ERP systems became a new factor against flexibility. In addition, failing rate in ERP projects implementation is high; however this rate is much more among SMEs (Morabito et al., 2005). Side effects of such failure are high due to time and budget that paid for ERP that increase the pessimism about information technology performance in SMEs.

Borner (2010) indicates that situational method engineering demonstrates the differences between different situations such as large and small enterprises in applying engineering methods. Thus, in ERP implementation field there are some differences that play a role in success of ERP systems. Some of differences are extracted from survey that has done within 20 SMEs and literature review that presented in the form of points:

Point 1: One of the main specifications of ERP systems is their flexibility that offers changing of existing processes in ERP over time. In order to using this attribute comprehensive, clear and standard documentation of enterprise business processes is required that often are absent in SMEs. Thus, one reason of preserving legacy systems is lack of documentation of business processes in SMEs that means there in no documentation of tasks in standard format. In addition, any solution should seriously consider legacy systems transformation road map because they are assumed as main source that contain enterprise knowledge and its experiences.

Point 2: In large enterprises adoption of ERP is planned and evaluated within long term strategic plans while SMEs tends to consider tactical steps.

Point 3: ERP vendors consider large enterprises requirements and also their capabilities in designing, developing and upgrading their systems much more than SME's concerns.

Point 4: SME's manager expects short implementing time and with containing all modules while large companies design a step by step within long process for ERP implementation.

Point 5: Large companies have few concerns about preserving legacy systems within ERP implementation road map. On the other hand customized legacy systems for SMEs have considered so critical that contains experts' 


\section{J. Computer Sci., 8 (8): 1389-1396, 2012}

experiences after years of editing and upgrading.

Point 6: ERP packages cost is not very important factor in large enterprises in contrary SMEs consider the cost as main factor.

SOA-SME compatibility: Service Oriented Architecture (SOA) proves its power in flexibility and agility. However these two specifications are also claimed by ERP systems but SOA has some important attributes such as loosely coupling, granularity, interoperability, reusability and ability to preserve existing systems (Kohlborn et al., 2009). It is easy to understand at the first glance that these capabilities will prepare better infrastructure than object oriented systems such as ERP. Especially, SMEs could mutate their IT infrastructure to get SOA benefits and cover ERP shortages that has been stated in many researches as ERP drawbacks (Themistocleous and Irani, 2000). If we would consider the 6 points that mentioned in previous section as necessities of SMEs to implement a success information system, an analysis between ERP and SOA capabilities could be done. Table 1 according to literature review presented above shows a perfect match between SOA to answer SMEs' requirements.

Table 1: ERP-SOA comparison based on SME's criteria

\begin{tabular}{lll}
\hline $\begin{array}{l}\text { Technology } \\
\text { challenges }\end{array}$ & ERP & SOA \\
\hline Point 1 & Not considered & Considered \\
Point 2 & Partially considered & Partially considered \\
Point 3 & Not considered & Considered \\
Point 4 & Not considered & Considered \\
Point 5 & Partially considered & Considered \\
Point 6 & Not considered & Partially considered \\
\hline
\end{tabular}

SOA could address the requirements in cost and ROI aspects because of its ability to exposing legacy systems as service by its nature (Gramignoli et al., 1999; Zach and Olsen, 2011).

Furthermore, about fully or partially implementation of the SOA in the enterprise that effect on budget factor as well as time to implementation factor, SOA has ability to divide the project to independent parts and then to small and reusable elements that appears as granular services with their fully comprehensive description and suitable cohesion. In addition, vendor dependency challenge is eliminated in SOA by ability of selecting any service as a building block of architecture from different vendor or by in house developing (SAP, 2009; Boerner and Goeken, 2009). In addition, to discuss in more details about SOA consistency with SME environment some criteria that mentioned above have presented in Table 2 as a comparison between six popular service identification methods and SMEs criteria.

This comparison emphasis on the ability of SOA to overcome the complexity challenge in large applications that aim to cover all enterprise tasks while in service architecture defining fine grain with limited tasks inside make the services more simple than ERP parts. Also services by using variety of methods such extracting a service from a limited area by plotting Create, Read, Update, Delete (CRUD) tasks or converting a table that represent a bounded data as a service and so on this architecture prepare an easy to achieve and not limited techniques for enterprises to get SOA's benefits (Baghdadi, 2006; Klose and Knackstedt, 2007; Jamshidi et al., 2008).

Table 2: Comparison of service identification methods based on SMEs challenges

\begin{tabular}{|c|c|c|c|c|c|c|}
\hline $\begin{array}{l}\text { Author } \\
\text { Challenges }\end{array}$ & $\begin{array}{l}\text { Klose and } \\
\text { Knackstedt (2007) }\end{array}$ & $\begin{array}{l}\text { Kohlmann and } \\
\text { Alt (2007) }\end{array}$ & Amsden (2007) & $\begin{array}{l}\text { Jamshidi et al. } \\
\text { (2008) }\end{array}$ & $\begin{array}{l}\text { Chen et al. } \\
(2005)\end{array}$ & Baghdadi (2006) \\
\hline $\begin{array}{l}\text { Lack of } \\
\text { experts }\end{array}$ & $\begin{array}{l}\text { Guide } \\
\text { lines }\end{array}$ & $\begin{array}{l}\text { Not } \\
\text { considered }\end{array}$ & $\begin{array}{l}\text { Not } \\
\text { considered }\end{array}$ & $\begin{array}{l}\text { Automate portion } \\
\text { of analysis steps }\end{array}$ & $\begin{array}{l}\text { Not } \\
\text { considered }\end{array}$ & $\begin{array}{l}\text { Used } \\
\text { automatic tool }\end{array}$ \\
\hline $\begin{array}{l}\text { Business IT } \\
\text { alignment }\end{array}$ & $\begin{array}{l}\text { Business process } \\
\text { and relationship } \\
\text { with stakeholders }\end{array}$ & $\begin{array}{l}\text { Define both IT } \\
\text { and business } \\
\text { process services }\end{array}$ & $\begin{array}{l}\text { Not } \\
\text { considered }\end{array}$ & $\begin{array}{l}\text { Extracting services } \\
\text { base on tasks }\end{array}$ & $\begin{array}{l}\text { Based on relations } \\
\text { power between }\end{array}$ & $\begin{array}{l}\text { Not } \\
\text { considered }\end{array}$ \\
\hline $\begin{array}{l}\text { Economic Issues } \\
\text { (Implement and } \\
\text { maintenance costs) }\end{array}$ & $\begin{array}{l}\text { Using legacy } \\
\text { systems as input }\end{array}$ & $\begin{array}{l}\text { Not } \\
\text { considered }\end{array}$ & $\begin{array}{l}\text { Not } \\
\text { considered }\end{array}$ & $\begin{array}{l}\text { Not } \\
\text { considered }\end{array}$ & $\begin{array}{l}\text { Not } \\
\text { considered }\end{array}$ & $\begin{array}{l}\text { Converting existing } \\
\text { tables to services }\end{array}$ \\
\hline $\begin{array}{l}\text { Lack of long- } \\
\text { term planning }\end{array}$ & $\begin{array}{l}\text { Lines of interaction } \\
\text { and line of visibility } \\
\text { of stakeholders } \\
\text { over time }\end{array}$ & $\begin{array}{l}\text { Sourcing } \\
\text { strategies }\end{array}$ & Not considered & Not considered & Not considered & Not considered \\
\hline Stability & Not considered & Not considered & Not considered & Not considered & Not considered & Not considered \\
\hline Complexity & Fine grain services & Not considered & Not considered & $\begin{array}{l}\text { Tasks-CRUD } \\
\text { operations-cohesion }\end{array}$ & Not considered & A service per table \\
\hline Interoperability & Fully supported & Fully supported & Fully supported & Fully supported & Fully supported & Fully supported \\
\hline
\end{tabular}




\section{J. Computer Sci., 8 (8): 1389-1396, 2012}

Through the comparison it is clear that SOA as architectural method can response the main SME challenges. In more than one SOA approaches, lack of experts has been tried to be covered by tools to automating the service identification from enterprise' business processes, or leverage existing databases in order to transform them as services (Baghdadi, 2006) (Jamshidi et al., 2008). Also, the comparison has revealed a focus on business-IT alignment in SOA methods that is a main challenge in SMEs that suffer due to this gap between their business and information systems even when they implement ERP system that not fully compatible with their business and enterprise structure.

According to the important SMEs poins that are extracted from servey results and the discussion section it is cleae that SOA sourower is in its flexibility and agility. However, these two specifications are also claimed by ERP systems but SOA is charactarized by attributes such as loosely coupling, granularity, interoperability, reusability and ability to preserve existing systems (Kohlborn et al., 2009). It is clear that these capabilities will prepare better infrastructure than object oriented based systems such existing ERP systems. Especially, SMEs could mutate their IT infrastructure to get SOA benefits and cover ERP shortages that has been stated in many researches as ERP drawbacks (Themistocleous and Irani, 2000). The points that mentioned in discussion section as necessities of SMEs and the systematic comparison in Table 2 indicate the SOA potentials in handling SMEs environment.

Also, the analysis between ERP and SOA based on those points shows the SOA compatibility in SMEs situations. Also, it could be concluded from comparison that has been done in Table 2 that previous methods confirm the SOA capabilties in addressing SME' challenges.

\section{CONCLUSION}

ERPs have been considered as popular solution to integrate enterprise IT infrastructure in last two decades. Over time, ERPs are produced and developed to address large enterprise challenges. Also, SMEs have been used ERPs to cover their shortages in agility and obtain enough ability to competence in their field. However ERP's inconsistency with SMEs' nature leads to lose the mentioned benefits and seems to have lost their competitive edge. Cost is another effective factor for SMEs as majority of ERPs forced high investment to SMEs.

In this study set of criteria of suitable information system of an SME was extracted from previous researches and discussed. Then, ERP success and failure reasons in SME's situation were discussed and also set of points as noticeable properties of ERPs in SMEs were presented. In addition, relationships of high level enterprise aspects and information system success factors were showed to demonstrate the pain points of SMEs in selecting an information system. In order to demonstrate the potential role of SOA in SMEs the SOA capabilities with emphasis on extracted SME's challenges were presented. Describing the advantages of the service and outcomes of them in comparison with ERP is demonstrated. Also, important changes that will force by that concept in an SME environment will be studied as well.

The results of this study provide SMEs with valuable analysis that will guide them to make correct and effective changes in their current information systems architecture. A model for implementing SOA based system based on SME's case studies could be considered as future work.

\section{REFERENCES}

Amsden, J., 2007. Modeling SOA: Part 1. Service specification. IBM Developer Works.

Baghdadi, Y., 2006. Reverse engineering relational databases to identify and specify basic Web services with respect to service oriented computing. Inform. Syst. Frontiers, 8: 395-410. DOI: $10.1007 / \mathrm{s} 10796-006-9007-2$

Boerner, R. and M. Goeken, 2009. Service identification in SOA Governance literature review and implications for a new method. Proceedings of the 3rd IEEE International Conference on Digital Ecosystems and Technologies, Jun. 1-3, IEEE Xplore Press, Istanbul, $\quad \mathrm{pp}$ : 588-593. DOI: 10.1109/DEST.2009.5276742

Borner, R., 2010. Applying situational method engineering to the development of service identification methods. Preceedings of the Americas Conference on Information Systems (AMCIS’10), Lima, Peru.

Botta-Genoulaz, V. and P.A. Millet, 2005. A classification for better use of ERP systems. Comput. Industry, 56: 573-587. DOI: 10.1016/j.compind.2005.02.007 
Brehm, N., L. Haak and D. Peters, 2009. Using FERP systems to introduce web service-based ERP systems in higher education. Lecture Notes Bus. Inform. Process., 37: 220-225. DOI: 10.1007/978-3-642-03424-4_27

Chen, F., S. Li, H. Yang, C.H. Wang and W.C.C. $\mathrm{Chu}, 2005$. Feature analysis for service-oriented reengineering. Proceedings of the 12th AsiaPacific Software Engineering Conference, Dec. 15-17, IEEE Xplore Press, pp: 8-8. DOI: 10.1109/APSEC.2005.67

Cruz-Cunha, M.M., 2010. Enterprise Information Systems for Business Integration in SMEs: Technological, Organizational and Social Dimensions. 1st Edn., Idea Group Inc, Hershey, PA., ISBN-10: 1605668923, pp: 573.

Damaskopoulos, P. and T. Evgeniou, 2003. Adoption of new economy practices by SMEs in Eastern Europe. Eur. Manage. J., 21: 133-145. DOI: 10.1016/S0263-2373(03)00009-4

Gramignoli, S., A. Ravarini and M. Tagliavini, 1999. A profile for the IT manager within SMEs. Proceedings of the 1999 ACM SIGCPR Conference on Computer Personnel Research, Apr. 8-10, ACM Press, New Orleans, LA, USA., pp: 200-208. DOI: 10.1145/299513.299677

Haddara, M. and O. Zach, 2011. ERP systems in SMEs: A literature review. Proceedings of the 44th Hawaii International Conference on System Sciences, Jan. 4-7, IEEE Xplore Press, Kauai, HI, pp: 1-10. DOI: 10.1109/HICSS.2011.191

Hopkins, R. and K. Jenkins, 2008. Eating the IT Elephant: Moving from Greenfield Development to Brownfield. 1st Edn., Addison-Wesley Professional, Upper Saddle River, NJ., ISBN-10: 0137130120, pp: 222.

Huang, Z. and P. Palvia, 2001. ERP implementation issues in advanced and developing countries. Bus. Process Manage. J., 7: 276-284. DOI: 10.1108/14637150110392773

Jamshidi, P., M. Sharifi and S. Mansour, 2008. To establish enterprise service model from enterprise business model. Proceedigns of the IEEE International Conference on Services Computing, Jul. 7-11, IEEE Xplore Press, Honolulu, HI., pp: 93-100. DOI: 10.1109/SCC.2008.52

Kelliher, F. and J.B. Henderson, 2006. A learning framework for the small business environment. J. Eur. Indus. Train., 30: 512-528. DOI: $10.1108 / 03090590610704385$
Klose, K. and R. Knackstedt, 2007. Identification of services - a stakeholder-based approach to soa development and its application in the area of production planning. European Research Center for Information Systems.

Kohlborn, T., A. Korthaus, T. Chan and M. Rosemann, 2009. Identification and analysis of business and software services-a consolidated approach. IEEE Trans. Services Comput., 2: 5064. DOI: 10.1109/TSC.2009.6

Kohlmann, F. and R. Alt, 2007. Business-driven service modeling-a methodological approach from the finance industry. University of Leipzig.

Levy, M. and P. Powell, 1998. SME flexibility and the role of information systems. Small Bus. Econ., 11: 183-196. DOI: 10.1023/A:1007912714741

Morabito, V., S. Pace and P. Previtali, 2005. ERP marketing and Italian SMEs. Eur. Manage. J., 23: 590-598. DOI: 10.1016/j.emj.2005.09.014

Nach, H. and A. Lejeune, 2008. Implementing ERP in SMEs: Towards an ontology supporting managerial decisions. Proceedings of the 2008 International MCETECH Conference on eTechnologies, Jan. 23-25, IEEE Xplore Press, Montreal, Que., pp: 223-226. DOI: 10.1109/MCETECH.2008.11

Nielen, A., T. Jeske and C.M. Schlick, 2010. Interdisciplinary assessment of process modeling languages applicable for small to medium-sized enterprises. RWTH Aachen University, Germany.

Oliveira, L.A.B.D., N.V.C.D. Vasconcelos, F.C.B.P. Queiroz, J.V. Queiroz and H.R. Hekis, 2011. Contribution of integrated management systems to university management: Case study of the federal university of rio grande do norte. J. Soc. Sci., 7: 415-422. DOI: 10.3844/jssp.2011.415.422

Quiescenti, M., M. Bruccoleri, U.L. Commare, S.N.L. Diega and G. Perrone, 2006. Business process-oriented design of Enterprise Resource Planning (ERP) systems for small and medium enterprises. Int. J. Product. Res., 44: 3797-3811. DOI: $10.1080 / 00207540600688499$

Sahran, F.A.G.S. and M. Mukhtar, 2010. ERP implementation challenges in small and medium enterprise: A framework and case study. Adv. Mater. Res., 138: 1636-1639.

SAP, 2009. Enterprise service design guide.

Tan, K.S., S.C. Chong, B. Lin and U.C. Eze, 2009. Internet-based ICT adoption: Evidence from Malaysian SMEs. Indus. Manage. Data Syst., 109: 224-244. DOI: $10.1108 / 02635570910930118$ 
Themistocleous, M. and Z. Irani, 2000. Taxonomy of factors for information system application integration. AIS Electronic Library (AISeL).

Yen, D.C., D.C. Chou and J. Chang, 2002. A synergic analysis for web-based enterprise resources planning systems. Comput. Standards Interfaces, 24: 337-346. DOI: 10.1016/S09205489(01)00105-2

Yuanqiang, X., P. Lok and S. Yang, 2009. The ERP implementation of SME in China. Proceedings of the 6th International Conference on Service Systems and Service Management, Jun. 8-10, IEEE Xplore Press, Xiamen, pp: 135-140. DOI: 10.1109/ICSSSM.2009.5174870

Zach, O. and D.H. Olsen, 2011. ERP system implementation in make-to-order SMEs: An exploratory case study. Proceedings of the 44th Hawaii International Conference on System Sciences (HICSS), Jan. 4-7, IEEE Xplore Press, Kauai, HI, pp: 1-10. DOI: 10.1109/HICSS.2011.190
Zaitun, A. and Z. Zaini, 2008. A web-based DSS for the evaluation of an ERP system. Proceedings of the 10th International Conference on Information Integration and Web-based Applications and Services, Nov. 24-26, ACM Press, Linz, Austria, pp: 698-701. DOI: 10.1145/1497308.1497448

Zdravkovi, M., M. Trajanovi and M. Miodrag, 2007. SOA-based approach to the enterprise resource planning implementation in small enterprises. Facta Universitatis-Series: Mech. Eng., 5: 97104. 